\title{
Pharmaceutical Technology Assessment: Perspectives from Payers
}

\author{
Musetta Y. Leung, PhD; Michael T. Halpern, MD, PhD, MPH; and Nathan D. West, MPA
}

\begin{abstract}
BACKGROUND: Advancements in biologics and personalized medicine and the implementation of national prescription drug policies have likely prompted payers to implement additional health technology assessment and cost-containment strategies. A payer's decision to provide coverage for a drug and its associated benefit design draws on information from many sources. However, there is an incomplete understanding of the process employed and the criteria applied in formulary assessments of pharmaceuticals by public and private health plans.
\end{abstract}

OBJECTIVES: To explore the pharmaceutical technology assessment (PTA) process to determine (a) who is involved in the decision making, (b) the timing and process of assessment and decision making, (c) the information and data that are considered, and (d) the outcomes of the assessment.

METHODS: Using a convenience sample drawn for exploratory purposes, we targeted health plans, pharmacy benefit management (PBM) companies, stand-alone Medicare Part D prescription drug plans, Medicaid agencies, and drug compendia. We used multiple approaches to identify and recruit medical and pharmacy directors responsible for prescription drug benefit design and formulary management. We conducted 1-hour semistructured telephone interviews with pharmacy benefit decision makers between November 2009 and April 2010 to address the PTA process, and they rated the importance of different sources and types of evidence. Qualitative analysis and descriptive statistics were used to explore coverage, preferred choice, and utilization management.

RESULTS: Thirty-two respondents representing 26 organizations participated in the interview. On a scale from 1 to 5 (not important to very important), interview respondents most valued published peer-reviewed studies, technology assessments, and internal data on drug utilization as sources of information (means $=4.68,4.22$, and 4.14 , respectively). Randomized controlled trials (RCTs) and systematic reviews/meta-analyses were the most valued types of evidence (means $=4.40$ and 3.66 , respectively); economic and observational data studies received low ratings (means $=3.19$ and 3.03, respectively). There was substantial variation in the process of evidence review, who and how individuals participated in the process, and outcomes related to formulary tier placement and utilization management.

CONCLUSIONS: U.S. health plan payers have established processes for PTA and prefer certain sources and types of evidence. Formulary decision makers value a broad range of information, and the specific factors influencing coverage and utilization management decisions vary across organizations and therapeutic areas.

J Manag Care Pharm. 2012;18(3):256-64

Copyright $\odot 2012$, Academy of Managed Care Pharmacy. All rights reserved.

\section{What is already known about this subject}

- The most important factors in formulary decision making have been reported to be safety, effectiveness, and efficacy, with FDA approval status, availability of alternatives, and acquisition cost of drugs also considered.

- Spooner et al. (2007) found that receipt of a dossier in the Academy of Managed Care Pharmacy (AMCP) Format for Formulary Submissions did not appear to influence the likelihood of a product attaining preferred formulary status.

- Nichol et al. (2007) found that nearly two-thirds of MCO respondents in their study modified the economic models provided with drug dossiers with their own population statistics.

\section{What this study adds}

- Established approaches are in place for pharmaceutical technology assessment (PTA), but PTA characteristics vary by organization. For example, the size of the pharmacy and therapeutics (P\&T) committee in our sample of 32 representatives from 26 health plans and pharmacy benefit management companies (PBMs) ranged from 7 to 25 people, and the duration of the meetings spanned from a few hours to 1.5 days.

- Evidence from randomized controlled trials (RCTs) was rated of high importance (mean $=4.40$ on 5-point scale), and retrospective observational (or secondary data) studies were rated of low importance (mean=3.03) for the type of information considered by the P\&T committees. Importance weighting for sources of evidence was high for peer-reviewed studies (mean $=4.68$ ) and low for unpublished abstracts (mean =2.03) and unpublished information from manufacturers (mean =2.10). AMCP Format dossiers and information from medical specialty societies were rated of moderate importance (mean $=3.21$ and 3.31, respectively).

- Only 1 payer (a nationally based plan) and 1 compendium graded the quality of evidence used in the PTA process in a systematic manner.
$\mathrm{T}$ he health care landscape has changed noticeably in the past decade. The rise of biologics and personalized medicine and an overall increase in prescription drug utilization have increased treatment options and costs for payers and patients. Moreover, initiation of prescription drug coverage for Medicare beneficiaries through stand-alone Medicare Part D prescription drug plans, Medicare Advantage prescription drug plans, or Medicare-subsidized employer plans caused major shifts in the sources of funds used to pay 
for drugs. ${ }^{1}$ These developments may have prompted payers to implement additional health technology assessment and costcontainment strategies.

A payer's decision in providing drug coverage and the associated benefit design draws on information from many sources. However, there is an incomplete understanding of the process employed and the criteria applied in formulary assessments of pharmaceuticals by public and private health plans. Recent published literature provides only limited information on formulary reviews (e.g., whether formulary decision makers use a systematic process to assess available evidence), types of evidence considered, timing for reviews, and other specifics of the formulary decision-making process. ${ }^{2-12}$ Moreover, private initiatives such as the Academy of Managed Care Pharmacy (AMCP) Format for Formulary Submissions dossiers for submitting evidence, federal initiatives in comparative effectiveness research (CER), and the passage of health care reform legislation in 2010 are likely to have significantly impacted the amount and type of health-related evidence available for decision makers.

In this study, we explored pharmaceutical technology assessment (PTA), a process that examines the short- and longterm health and economic outcomes of adopting biologic and pharmaceutical products. The study's goals were to identify the following: (a) who is involved in the decision making, (b) the timing and process of assessment and decision making, (c) the information and data that are considered, and (d) the outcomes of the assessment.

\section{Methods}

To identify potential participants, we employed a convenience sampling methodology drawn for exploratory purposes and selected organizations in different categories based on organization size, covered populations, market share, and size and geographic dispersion of coverage areas. Target organizations included national and regional health plans, pharmacy benefit management (PBM) companies, stand-alone Medicare Part D prescription drug plans, Medicaid agencies, and the 4 compendia approved by the Centers for Medicare \& Medicaid Services (CMS). We used multiple approaches to identify and recruit medical and pharmacy directors responsible for prescription drug benefit design and formulary management. We used professional relationships and recruiting services, as well as conducted "cold calling," to recruit participants for this study. For a subset of organizations, we sought to identify both a medical and pharmacy director from the same organization.

We conducted 1-hour semistructured interviews between November 2009 and April 2010 to explore the decision-making process for pharmaceutical adoption and coverage decisions. The interview guide was developed after an extensive review of published and grey literature (e.g., poster abstracts, presentations, letters to the editor) to identify factors that had been reported to be important in formulary decision making These questions were pilot tested with 1 retired and 1 active pharmacy director from commercial health plans who had experience with pharmacy and therapeutics (P\&T) committees. A number of interview questions were revised upon their feedback. Each interview was led by an experienced researcher and focused on the objectives of this study, including what information and data are considered for formulary decision making, who is involved, what is in the PTA process, and what are the end results of the PTAs. During the interview, we also asked respondents to complete 5-point Likert-type rating scales regarding the importance of different sources and types of information used in the PTA process. The interview guide and the rating scales are included in the Appendix.

\section{Data Analysis}

Following each interview, notes were transcribed and coded using the NVivo software package (QSR International, Doncaster, Victoria Australia) for qualitative data analysis. Responses were coded by question, by respondent (i.e., pharmacy director versus medical director), and by organizational type (i.e., national health plan, regional health plan, PBM, or other) for pattern analysis. The rating scales on the types and sources of data obtained from the interviews were evaluated using descriptive and statistical analyses using SPSS (IBM SPSS, Armonk, NY). Frequencies of ratings, averages, standard deviations, and interquartile ranges were ascertained. Comparison of means using t-tests and analysis of variance (ANOVA) were conducted to reflect significant differences by respondent type and organization type, respectively.

\section{Results}

\section{Respondent Characteristics}

We contacted key decision makers at 34 payers, payer intermediaries, and drug compendium organizations; 32 respondents from 26 organizations were interviewed (Table 1). For the purposes of this study, a drug compendium was defined as a listing of prescription medications and their indications that is recognized by CMS for making coverage decisions. Among the 14 medical directors and 17 pharmacy directors who participated, 6 pairs were from the same commercial health plans. Altogether, our respondent organizations provided pharmacy management or health care coverage for up to 125 million individuals or $40 \%$ of the U.S. population (although this total likely includes some "double counting" of covered lives). Our sample of health plans offered employer-based policies, individual coverage policies, and Medicare Advantage and Medicaid managed care products. Two of the 3 Medicaid agencies that responded participated in the Drug Effectiveness Review Project (DERP), a collaborative partnership among states and other government and nonprofit entities that conducts systematic evidence-based reviews of pharmaceuticals. Our attempts to identify and 
Pharmaceutical Technology Assessment: Perspectives from Payers

\section{TABLE 1 Number of Organizations and Interview Respondents}

\begin{tabular}{|c|c|c|c|c|}
\hline & $\begin{array}{c}\text { Target } \\
\text { Number }\end{array}$ & $\begin{array}{c}\text { Method of } \\
\text { Recruitment }\end{array}$ & $\begin{array}{l}\text { Number } \\
\text { Contacted }\end{array}$ & $\begin{array}{c}\text { Number Responding } \\
\text { to Interview }\end{array}$ \\
\hline Number of organizations & 24 & & 34 & 26 \\
\hline National health plans ${ }^{a}$ & 6 & \multirow{5}{*}{$\begin{array}{l}\text { Professional } \\
\text { research recruiting } \\
\text { service + leveraged } \\
\text { existing professional } \\
\text { relationships }\end{array}$} & 7 & 7 \\
\hline Regional health plans ${ }^{a}$ & 5 & & 9 & 9 \\
\hline Self-insured large employer or employer coalition & 2 & & 2 & 0 \\
\hline Pharmacy benefit managers & 2 & & 4 & 4 \\
\hline Medicare prescription drug plans & 2 & & 1 & 1 \\
\hline Medicaid program & 3 & "Cold calling" & 7 & 3 \\
\hline CMS-designated compendia & 4 & "Cold calling" & 4 & 2 \\
\hline Number of respondents & 48 & & 39 & 32 \\
\hline Medical directors & 24 & & 15 & 14 \\
\hline Pharmacy directors & 24 & & 21 & 17 \\
\hline Other & - & & 3 & 1 \\
\hline
\end{tabular}

a Four national health plans and 2 regional health plans had duplicate interviews (i.e., we separately interviewed 2 people).

CMS $=$ Centers for Medicare $\&$ Medicaid Services

interview 2 self-insured large employers that may conduct their own PTA revealed that both employers outsourced their PTA and drug benefit decision-making processes.

\section{Who Is Involved and What Is the Process of Assessment?}

Both commercial insurers (representing private sector and Medicare Advantage plans) and Medicaid respondents indicated that multidisciplinary teams are actively involved in pharmaceutical technology assessment, and this is performed at fixed intervals ranging from monthly to quarterly, with a meeting duration varying from 2 hours to 1.5 days. For the commercial health plans that conducted their own assessments, staff clinical pharmacists were assigned to a particular product or a class of drugs for each meeting. Their responsibilities were to sift through all of the information and evidence related to the drug or biologic at hand, synthesize the findings, and prepare the information (often called monographs, pharmacy clinical policy bulletins, or presentations) that would be reviewed and presented at the organizations' P\&T or drug review committee meetings. In many cases, the pharmacy staff would also provide the recommendation for how the drug under review should be covered (e.g., tier placement, step edit or prior authorization requirements). However, the decision-making authority for pharmaceutical adoption and coverage decisions rested largely with the P\&T committees. Three of the small- to midsized health plans that we interviewed outsourced this review to a PBM or another third-party organization.

Members of P\&T committees included medical directors and pharmacy directors, as well as internal or external primary care and subspecialist physicians, such as rheumatologists, cardiologists, oncologists, and psychiatrists. All organizations reviewed new drugs within 90 days of launch and considered updates and reviews of drug or therapeutic classes periodically.
Despite having similar individuals involved in the drug review process, the P\&T committee makeup and timing of review differed across organizations. First, the number of people serving on P\&T committees ranged from 7 to more than 25 (mode $=12$ people), with national commercial plans having a higher number of P\&T participants (between 12 to 25 people). In most of our responding organizations, only voting members attended the meetings, while a handful of organizations allowed nonvoting patient advocates, staff who prepared the presentations, or clients to be present.

P\&T meeting materials prepared by the pharmacy staff were made available to committee members up to 2 weeks prior to the P\&T meeting. All organizations we interviewed reached consensus on pharmaceutical adoption decisions through simple majority vote. However, the formality of how the committee reached a quorum-a term used by multiple plans to stress the minimum number of people needed for reaching a consensus - to carry a coverage decision forward varied. A few of the health plans carefully reviewed and discussed all of the available evidence on a drug and at times held spirited debates before reaching a consensus for coverage determinations. In these cases, official votes were not necessary, since the committee reached consensus through deliberations. Other health plans carried out official votes with a simple "yes" or "no" or a show of hands. Almost all health plans said it was rare for the committee to not reach a true consensus regardless of the formality of a majority rules vote.

\section{What Information and Data Are Considered?}

While a range of evidence was used for formulary decisions, the value placed on different sources and types of evidence was often subjective and, thus, could potentially influence the objectivity of decisions. Using Likert-type scales, we obtained 


\section{TABLE 2 Descriptive Statistics of Respondent Ratings of the} Importance ${ }^{a}$ of Sources and Types of Evidence

\begin{tabular}{|c|c|c|c|c|c|c|c|c|}
\hline Variable $^{b}$ & $\mathrm{~N}$ & Mean & SD & Min & $\begin{array}{c}25 \text { th } \\
\text { Percentile }\end{array}$ & $\begin{array}{c}50 \text { th } \\
\text { Percentile }\end{array}$ & $\begin{array}{c}\text { 75th } \\
\text { Percentile }\end{array}$ & $\operatorname{Max}$ \\
\hline \multicolumn{9}{|l|}{ Sources of evidence } \\
\hline $\begin{array}{l}\text { Published peer-reviewed studies (e.g., clinical trial, systematic reviews, } \\
\text { observational studies, retrospective database studies meta-analysis, } \\
\text { pharmacoeconomics) }\end{array}$ & 30 & 4.68 & 0.59 & 3 & 4 & 5 & 5 & 5 \\
\hline Technology assessments (such as comparative effectiveness studies) & 30 & 4.22 & 0.74 & 3 & 4 & 4 & 5 & 5 \\
\hline Internal data on utilization & 28 & 4.14 & 0.93 & 1 & 4 & 4 & 5 & 5 \\
\hline Information from within the organization (e.g., management) & 27 & 3.43 & 1.18 & 1 & 3 & 4 & 4 & 5 \\
\hline Published peer-reviewed abstracts & 29 & 3.38 & 1.05 & 1 & 3 & 4 & 4 & 5 \\
\hline Information from medical specialty societies & 31 & 3.31 & 0.99 & 1 & 3 & 3 & 4 & 5 \\
\hline AMCP Format dossiers (for managed care organizations) & 28 & 3.21 & 0.99 & 1 & 3 & 3 & 4 & 5 \\
\hline Reports from other organizations (e.g., DERP [for Medicaid agencies]) & 30 & 2.87 & 1.11 & 1 & 2 & 3 & 4 & 5 \\
\hline Information from competing health plans & 31 & 2.66 & 1.22 & 1 & 2 & 3 & 4 & 5 \\
\hline Unpublished information provided directly by the manufacturer & 30 & 2.10 & 0.99 & 1 & 1 & 2 & 3 & 4 \\
\hline Unpublished abstracts & 29 & 2.03 & 1.02 & 1 & 1 & 2 & 3 & 4 \\
\hline \multicolumn{9}{|l|}{ Types of evidence } \\
\hline Randomized control trials & 30 & 4.40 & 0.89 & 1 & 4 & 5 & 5 & 5 \\
\hline Systematic reviews or meta-analyses (including comparative effectiveness studies) & 29 & 3.66 & 0.94 & 1 & 3 & 4 & 4 & 5 \\
\hline Review articles & 31 & 3.55 & 0.99 & 1 & 3 & 4 & 4 & 5 \\
\hline Professional society guidelines & 31 & 3.53 & 1.06 & 1 & 3 & 4 & 4 & 5 \\
\hline Prospective observational (or secondary data) studies & 31 & 3.31 & 1.01 & 1 & 3 & 4 & 4 & 5 \\
\hline Budget impact & 28 & 3.27 & 1.38 & 1 & 2 & 3 & 5 & 5 \\
\hline Cost and economic studies & 28 & 3.09 & 1.20 & 1 & 2 & 3 & 4 & 5 \\
\hline Retrospective observational (or secondary data) studies & 29 & 3.03 & 1.05 & 1 & 3 & 3 & 4 & 5 \\
\hline
\end{tabular}

separate ratings for potential sources of evidence (i.e., where evidence is obtained) versus the types of evidence used, although there were overlaps in these 2 categories.

Table 2 shows the average rating among all respondents for each source of evidence examined on a scale of 1 (not important) to 5 (very important). Respondents gave published peerreviewed studies and published technology assessments (e.g., from the Agency for Healthcare and Research Quality [AHRQ], Hayes, or ECRI Institute) mean scores of 4.7 and 4.2, respectively, and medical directors valued technology assessment 0.6 point higher than did pharmacy directors (data not shown). For all other sources of evidence listed, some respondents rarely considered the information, while others placed tremendous importance on them. For example, information from similar entities (e.g., competing health plans) and from medical societies were each rated as moderately important (means scores of 2.7 and 3.3, respectively), but responses varied from 1 to 5 . The majority of payers indicated that their internal data on drug utilization were also important sources of information for PTA (mean = 4.1) and were used whenever available. In fact, our stratified analysis showed that pharmacy directors placed higher importance (by 0.7 point) on internal data than did medical directors (data not shown). However, when we further probed the respondents, they revealed that most internal health plan data provided information only on pharmaceutical costs and volume dispensed because data needed for outcomes analysis (i.e., pharmacy and medical data) were not linked in a majority of health plans that participated in this study. Despite all respondents highly valuing this coupled information, only representatives from 2 health plans responded that they conduct such analyses regularly.

Respondents were also asked to rate the importance of various types of evidence used in formulary assessments. In general, respondents placed the highest value on "randomized control trials" (mean=4.4), followed by "systematic reviews or meta analyses (including comparative effectiveness studies)" (mean = 3.7), "review articles" (mean = 3.6), and "professional society guidelines" (mean $=3.5$ ). "Observational (or secondary data) studies" (both prospective and retrospective) received lower ratings (mean $=3.3$ and 3.0). However, payers in general did not express concerns about using their own observational data (i.e., internal health plan data) for formulary decision making. 


\section{What Are the Outcomes of the Assessment?}

For health plans, PBMs, and Medicaid drug review committees, the result of PTA may include coverage, tier placement, and utilization management recommendations (e.g., prior authorization or step therapy). While formulary inclusion, tier placement, or prior authorization requirements were typically recommended prior to the P\&T meeting by staff clinical pharmacists, P\&T committee members could accept or modify these recommendations. Our respondents stated that tier assignment decisions were largely based on expected clinical outcomes, and most payers placed a new (branded) pharmaceutical into the second or "preferred brand" tier if it was expected to provide superior outcomes relative to its comparators in the same drug class. If a drug's outcomes were expected to be comparable to existing products in that particular drug class, the product was usually placed into the third or "nonpreferred" drug tier and later reviewed following real-world experience with the drug. Conversely, 2 respondents said their organizations defaulted all new products into the second tier initially and reserved the third tier for products that demonstrated lower positive outcomes relative to cost over time. Respondents varied in how much pharmaceutical cost weighted relative to other factors such as strength of evidence or expected outcomes. One medical director stated that tier assignment was based on the drug's efficacy and projected clinical outcomes, while cost was secondary and usually considered for more crowded classes of drugs (e.g., for hypertension or rheumatoid arthritis). However, another medical director stated that cost was a predominant factor in all drug evaluation scenarios.

There was also substantial variation among our respondents regarding whether and how P\&T decisions affected contract and rebate negotiations with manufacturers. Nine respondents mentioned having a team that met separately from the P\&T committee to handle rebates and discounts with manufacturers, and 8 respondents indicated that rebate discussions always preceded P\&T decisions. Nevertheless, $40 \%$ of our respondents stated that manufacturer costs and rebates had bearing on initial P\&T decisions regarding tier placement and that the tier placement and rebate negotiations were iterative processes. In some organizations, decisions to require prior authorization were made in tandem with formulary tier placement of a new pharmaceutical; for others organizations, these decisions were made by the organization's management after completion of the $P \& T$ process.

\section{Medicaid}

While Medicaid programs do not maintain formularies similar to those in the commercial sector, Medicaid programs can apply preferred drug lists (PDLs) to differentiate drugs subject to a prior authorization process as a condition of coverage or payment. Each Medicaid organization we interviewed used a somewhat different process for determining preferred drug status and utilization management of outpatient drugs. However, the 2 representatives from Medicaid agencies in our sample who participated in the DERP utilized a PDL, while oversight and decision making rested with the PDL committee or drug review committee (DRC). The committees evaluated evidence-based, systematically reviewed reports developed by federally designated evidence-based practice centers (EPC). One of the non-DERP participating Medicaid states also valued the DERP systematic reviews available in the public domain. This state Medicaid agency frequently included these reports as a source of evidence along with other important sources from the peer-reviewed literature and their own internal data on utilization. This agency also called upon their contracted PBM to supply a portion of the evidence information used for their P\&T committee reviews, but the internal pharmacy staff used their discretion to include or exclude evidence gathered from multiple sources, including input provided from the PBM. The PBM also helped to facilitate the quarterly P\&T committee meetings by posting the drug monographs prepared by the pharmacy department staff to a website about 2 to 4 weeks prior to the meetings.

\section{Discussion}

Prior literature has cited both the evidence used by and burden placed on formulary committees in their drug evaluation process. As stated by Lyles and Watkins (2007), "a formulary placement decision is the result of numerous considerations, such as the clinical need for the product under review; the existence of viable alternatives; safety profiles; all else being equal, the relative costs for alternative products; and the evidence and analysis provided by a credible dossier." ${ }^{13}$ Our study aimed to provide an updated and comprehensive understanding of how pharmaceutical technologies are assessed by key decision makers and to identify some of the nuances in the formulary decision-making process. The interviews and rating scales provided an opportunity to qualitatively and quantitatively understand how key decision makers value certain drug characteristics and sources of information in determining coverage for pharmaceutical products.

All respondents indicated that their organizations used a structured approach to gather and review evidence. Each of the organizations we interviewed had a system in place to review drugs and biologics that come onto the market, whether by using their own pharmacy team for the initial drug reviews and bringing the information to the P\&T committee for voting, or by relying on an outside PBM to review products and to provide the coverage recommendations. In general, respondents preferred evidence that had gone through the peer-review process, and journal prestige was cited as an important factor. Our rating scales also supported the finding by Spooner et al. (2007) that the availability of AMCP Format-based dossiers had limited influence in the formulary decisions. ${ }^{6}$ We also found 
that only 1 payer (a nationally based plan) and 1 compendium graded evidence used in the PTA process in a systematic manner, where "grades" are given to the reviewed products based upon their supporting studies' rigor, validity, and quality. The 2 respondents indicated that, when reviewing studies, their organizations graded based on the quality and source of the evidence, including peer review, threats to validity, design of the randomized controlled trials (RCTs), and how the data were analyzed (e.g., whether the study used an intent-to-treat analysis).

Respondents described a number of shortcomings with evidence used for PTAs. The most often cited complaint was the lack of head-to-head or direct comparative effectiveness studies, given that most clinical trials for pharmaceuticals are against placebo. Some study participants recognized a recent trend towards increased availability of head-to-head studies, although this was viewed as nascent and still lacking in quantity and quality. Another common challenge cited by respondents was how to make decisions when the available evidence is inconsistent or inadequate. When high-quality RCTs or other studies were inadequate, decision makers often relied on anecdotal findings or expert opinion. The use of decisionanalytic models was employed only by a small number of payer organizations to simulate drug treatment comparisons when the available evidence was deemed insufficient. Our study also provided updated evidence that a number of payers are increasingly using pharmacoeconomics data, but internal and external factors cited elsewhere continue to limit their usefulness in the formulary decision-making process. ${ }^{12}$

We also found some variability and a number of apparent inconsistencies in the described approaches to formulary decision making. Respondents stated their intention to make formulary decisions was not only based on "best evidence," but also on "best value" for their payers and members. Yet, these decision makers expressed a substantial degree of variability in the role that costs play in the PTA process, both dependent on the organization and by the therapeutic area. Also, while there was a strong desire for head-to-head comparative effectiveness data, our respondents only gave moderate preference for observational data. Although observational studies may provide additional comparative information between treatment alternatives in real-world use, many of our respondents assigned lower importance to observational data compared with high preference for RCTs (mean scores of 3.3 for prospective and 3.0 for retrospective studies, respectively), citing research design flaws as threats to validity and credibility.

\section{Limitations}

Foremost among the limitations of this study are threats to internal validity and generalizability. First, because each state creates its own set of mandates by which health plans have to abide in caring for the state's Medicaid population, the information collected from the 3 participating Medicaid agencies may not be generalizable. Second, our small sample size and variability in approaches for PTA and in each plan's unique set of obligations (e.g., plan rules/charter, for-profit vs. nonprofit status, external clients, target patient populations, and so forth) may also limit generalizability. Third, our results may not be representative of the universe of private health plans because we used a purposive sample rather than a random sample of respondents and employed multiple uses of convenience sampling to target the specific types of organizations identified. Fourth, participation was self-selected, which may have introduced another source of bias. Fifth, the participants in our study may not have been the individuals most knowledgeable about the details of product evaluation in the P\&T process in their organizations (e.g., clinical pharmacists often provide the staff support for the P\&T process and evaluate drugs for the health plan). Future studies may benefit from surveying a larger randomly selected pool of PTA decision makers that was beyond the scope for the present study, potentially including other medical and pharmacy personnel and external members of the P\&T committees.

\section{Conclusions}

Despite limitations, this study provides important insights into how PTAs are currently conducted. The processes and evidence used in making pharmaceutical coverage decisions varied substantially among U.S. payers. The variation in PTA characteristics and process could affect reimbursement, patient access, and potentially heath care outcomes across health plans. As decision-maker requests for evidence expand (e.g. CER), and the sources of observational data and information from new electronic health records or claims databases are available, it is uncertain how and to what extent this information will be used in the PTA process.

\section{Authors}

MUSETTA Y. LEUNG, PhD, is Senior Health Services Researcher, RTI International, Waltham, Massachusetts; MICHAEL T. HALPERN, MD, PhD, MPH, is Senior Fellow, RTI International, Washington, DC; and NATHAN D. WEST, MPA, is Research Health Analyst, RTI International, Research Triangle Park, North Carolina.

AUTHOR CORRESPONDENCE: Musetta Y. Leung, PhD, RTI International, 1440 Main St., Ste. 310, Waltham, MA 02451-1623. Tel.: 781.434.1730; E-mail: mleung@rti.org. 


\section{ACKNOWLEDGEMENTS}

The authors thank the following 3 individuals for their assistance with this project: Laura Morgan, MA, is Research Health Analyst, RTI International, Research Triangle Park, North Carolina; at the time this research was conducted, Eric C. Faulkner, MPH, was Senior Director of U.S. Market Access and Reimbursement, RTI Health Solutions, Research Triangle Park, North Carolina; and Charlotte Reardon, BA, was Research Analyst, RTI International, Waltham, Massachusetts. The authors also acknowledge the National Pharmaceutical Council (NPC) for providing assistance in study design and comments on the study reports that led to this manuscript.

\section{DISCLOSURES}

This research was based on a study funded by NPC, whose members are brand-name pharmaceutical manufacturers. NPC did not have any role in data collection or analysis and did not have the right to approve or disapprove the final manuscript. All research and manuscript preparation were performed by individuals at RTI International. Preliminary results of the rating scales were presented as a poster at the annual meeting of the International Society of Pharmacoeconomics and Outcomes Research (ISPOR) on May 18, 2010, in Atlanta, Georgia.

Leung and Halpern conceived and designed the study with the assistance of West and Faulkner. Leung and West collected the data, with assistance from Halpern, Faulkner, Morgan, and Reardon. Leung and Halpern interpreted the data with the assistance of West, Faulkner, Morgan, and Reardon. Leung and Halpern wrote the manuscript with the assistance of West and Faulkner, and Leung and Halpern revised the manuscript after peer review.

\section{REFERENCES}

1. Catlin A, Cowan C, Hartman M, Heffler S. National health spending in 2006: a year of change for prescription drugs. Health Aff (Millwood). 2008;27(1):14-29. Available at: http://content.healthaffairs.org/content/27/1/14.full.pdf+html. Accessed March 7, 2012.

2. Robinson JC. Insurers' strategies for managing the use and cost of biopharmaceuticals. Health Aff (Millwood). 2006;25(5):1205-17. Available at: http://content.healthaffairs.org/content/25/5/1205.full.pdf+html. Accessed March 7, 2012.
3. Giaquinta D. The changing timetable for the evaluation of new products for formulary consideration. Manag Care Interface. 2003;16(2):24-25,28.

4. Levinson W, Laupacis A. A call for fairness in formulary decisions. Arch Intern Med. 2006;166(1):16-18.

5. Fullerton DS, Atherly D, Sullivan SD. Showing outcomes and proving value brings success. Manag Care Interface. 2001;14(6):63-65,71.

6. Spooner JJ, Gandhi PK, Connelly SB. AMCP Format dossier requests: manufacturer response and formulary implications for one large health plan. J Manag Care Pharm. 2007;13(1):37-43. Available at: http://amcp.org/data/ jmcp/37-43.pdf.

7. Langley PC. Formulary submission guidelines for Blue Cross and Blue Shield of Colorado and Nevada. Structure, application and manufacturer responsibilities. Pharmacoeconomics. 1999;16(3):211-24.

8. Garber AM. Evidence-based coverage policy. Health Aff (Millwood). 2001;20(5):62-82. Available at: http://content.healthaffairs.org/content/20/5/62.full.pdf. Accessed March 7, 2012.

9. Holtorf AP, Watkins JB, Mullins CD, Brixner D. Incorporating observational data into the formulary decision-making process-summary of a roundtable discussion. J Manag Care Pharm. 2008;14(3):302-08. Available at: http://www.amcp.org/data/jmcp/JMCPMaga_Apri108_302-308.pdf.

10. Bozzette SA, D'Amato R, Morton S, Harris K, Meili R, Taylor R. Pharmaceutical technology assessment for managed care: current practice and suggestions for improvement. RAND report prepared for SanofiSynthelabo Inc. August 2001. Available at: http://www.rand.org/pubs/monograph_reports/2005/MR1206.pdf. Accessed March 7, 2011.

11. Nichol MB, Knight TK, Epstein J, Honda DH, Tretiak R. Opinions regarding the Academy of Managed Care Pharmacy dossier submission guidelines: results of a small survey of managed care organizations and pharmaceutical manufacturers. J Manag Care Pharm. 2007;13(4):360-71 Available at: http://www.amcp.org/WorkArea/DownloadAsset.aspx?id=7568

12. Suh D, Okpara IR, Agnese WB, Toscani M. Application of pharmacoeconomics to formulary decision making in managed care organizations. Am J Manag Care. 2002;8(2):161-69. Available at: http://www.ajmc.com/media/ pdf/AJMC2002febSuh161_169.pdf. Accessed March 7, 2012.

13. Lyles A, Watkins JD. Manufacturer response to AMCP Format dossier requests. J Manag Care Pharm. 2007:13(3):290-91. Available at: http://www. amcp.org/WorkArea/DownloadAsset.aspx?id=7564. 


\section{APPENDIX Current Practices in Pharmaceutical Technology Assessment by Commercial Managed} Care Plans, Medicare/Medicaid, and Government Designated Compendia

\section{Commercial Payer/Payer Intermediary Interview Guide}

Background: RTI International has been tasked to examine the current practices in pharmacy and therapeutics decision making and pharmaceutical technology assessment among payers and their intermediaries. The purpose of our study and this telephone interview is to learn about the way drugs and biologics are evaluated and adopted in organizations like yours. We want to find out this information to understand how the process works, and what information is currently missing but you'd like to have in hand when key decision-makers, like yourself, make decisions. This study is being funded by the non-profit independent foundation, the National Pharmaceutical Council, and is being carried out by us, RTI International. We are contacting health plans, pharmacy benefit managers, Medicaid agencies, and government compendia to gather this information.

The interview has two parts: this l-hour telephone interview, and a follow-up survey that we ask that you complete within the next week; the survey should take no more than 1 hour to complete. Please complete and send us back the survey, as the information you provide will be integral to what we will learn on this phone call

Taking part in the telephone interview and the follow-up survey is voluntary. Any remarks from the discussion or the survey will remain private and confidential, and identifiable information will never be shared with the funder or with the general public. Let me stress that we will not share any attributable or identifiable information you give us with anyone other than project staff. We will audio record the telephone conversations to help us track our interviews, but the recording will be destroyed afterwards.

Would you like to take part in this study?

1. GENERAL OVERVIEW - BASIC ORGANIZATIONAL INFORMATION

la. Briefly describe your organization, lines of business (\% commercial or employer-based; \% Medicare or State Medicaid), plan size/covered lives, coverage areas, risk sharing arrangements

1b. Describe your role (key informant) in the organization. What is your title, responsibilities, longevity in your role and with the organization?

lc. What is your organization's or your typical payers' basic reimbursement and tier structure for prescription drugs? How much does it vary by lines of business?

2. WHO IN THE ORGANIZATION IS INVOLVED AND/OR RESPONSIBLE FOR MAKING PHARMACEUTICAL ADOPTION AND COVERAGE DECISIONS?

2a. Does your organization conduct pharmaceutical technology assessment for your payers?

If not, please skip to question 4

If so, what types of people are involved in technology assessment in your organization? How many are medical vs. non-medical personnel?

2b. P\&T Committee (if applicable) - describe the make-up of the committee. Who internally serves on the committee vs. external members?

2c. How often do you meet (e.g. ad hoc, weekly, monthly, quarterly, etc.)?

2d. How is consensus reached?

2e. What other stakeholders (internal or external) are involved in the technology assessment process for pharmaceuticals? What types of input do they provide?

3. WHAT INFORMATION IS USED IN THE TECHNOLOGY ASSESSMENT PROCESS IN YOUR ORGANIZATION?

3a. What sources of evidence are used and how are they weighted?

\begin{tabular}{|c|c|c|c|c|c|c|}
\hline \multirow{2}{*}{$\begin{array}{l}\text { Source of evidence } \\
\text { Published peer-reviewed studies (e.g., clinical trial, systematic reviews, observational } \\
\text { studies, retrospective database studies meta-analysis, pharmacoeconomics) }\end{array}$} & \multicolumn{6}{|c|}{$\begin{array}{l}\text { Weighting scale (1-5; NA) } \\
\text { NA = Not applicable } \\
1=\text { Not important (Never use) } \\
5 \text { = Very important (Indispensable) }\end{array}$} \\
\hline & 1 & 2 & 3 & 4 & 5 & NA \\
\hline Published peer-reviewed abstracts & 1 & 2 & 3 & 4 & 5 & NA \\
\hline Unpublished abstracts & 1 & 2 & 3 & 4 & 5 & NA \\
\hline Unpublished information provided directly by the manufacturer & 1 & 2 & 3 & 4 & 5 & NA \\
\hline Technology assessments (such as comparative effectiveness studies) & 1 & 2 & 3 & 4 & 5 & NA \\
\hline Information from competing health plans & 1 & 2 & 3 & 4 & 5 & NA \\
\hline Information from within the organization (e.g., management) & 1 & 2 & 3 & 4 & 5 & NA \\
\hline Information from medical specialty societies & 1 & 2 & 3 & 4 & 5 & NA \\
\hline AMCP Format dossiers (for managed care organizations) & 1 & 2 & 3 & 4 & 5 & NA \\
\hline Reports from other organizations [e.g., DERP (for Medicaid agencies)] & 1 & 2 & 3 & 4 & 5 & NA \\
\hline Internal data on utilization & 1 & 2 & 3 & 4 & 5 & NA \\
\hline
\end{tabular}

\section{3b. Name other types of sources you also use that are not listed here}

3c. If you use technology assessments from other organizations in your decision making, which is reflected above, which organizations' information do you use? (E.g., AHRQ, BCBS TEC, Hayes, ECRI, other)

3d. How much weight does your organization apply to each of the following types of evidence when conducting a technology assessment?

\begin{tabular}{|c|c|c|c|c|c|c|}
\hline \multirow{2}{*}{$\begin{array}{l}\text { Types of evidence (note: may overlap) } \\
\text { Professional society guidelines }\end{array}$} & \multicolumn{6}{|c|}{$\begin{array}{c}\text { Weighting scale (1-5; NA) } \\
\text { NA = Not applicable } \\
1=\text { Not important (Never use) } \\
5=\text { Very important (Indispensable) }\end{array}$} \\
\hline & 1 & 2 & 3 & 4 & 5 & NA \\
\hline Review articles & 1 & 2 & 3 & 4 & 5 & NA \\
\hline Randomized control trials & 1 & 2 & 3 & 4 & 5 & NA \\
\hline Prospective observational (or secondary data) studies & 1 & 2 & 3 & 4 & 5 & NA \\
\hline Retrospective observational (or secondary data) studies & 1 & 2 & 3 & 4 & 5 & NA \\
\hline Systematic reviews or meta-analyses (including comparative effectiveness studies) & 1 & 2 & 3 & 4 & 5 & NA \\
\hline Cost and economic studies & 1 & 2 & 3 & 4 & 5 & NA \\
\hline Budget impact & 1 & 2 & 3 & 4 & 5 & NA \\
\hline
\end{tabular}




\section{APPENDIX Current Practices in Pharmaceutical Technology Assessment by Commercial Managed} Care Plans, Medicare/Medicaid, and Government Designated Compendia (continued)

3e. Describe the general process by which you evaluate the evidence.

- At what point in time are the various types of studies/information considered?

- To what extent do you use prospective vs. retrospective studies in making decisions?

- Under what circumstances are direct head to head studies a requirement vs. indirect studies?

- How do you see this changing in your organization in the future?

4. HOW ARE PHARMACEUTICAL ADOPTION AND COVERAGE DECISIONS MADE?

Process

4a. Describe the specific steps that your organization takes in the health technology assessment process or coverage decisions for drugs.

4b. Does your review process vary by, or are there special considerations for:

- Oral and self administered vs. patient injectables vs. physician administered drugs

- Diseases/conditions with none/few treatment alternatives vs. several treatment alternatives

- Drugs that are lifestyle focused (e.g., Viagra, Cialis)

- Preventive health care drugs with only long-term positive impact

- smoking cessation drugs: Zyban (Wellbutrin) and Chantix (varenicline), or

- (optional); drugs to prevent osteoporosis: Fosamax, Boniva, or Evista

- (optional): drugs for secondary prevention: hypertension drugs

- Drugs that considered personalized medicine, like Herceptin for treating breast cancer among women with a certain biomarker

4c. Do you have a specialty tier? Is this administered internally or as a carve-out? Are there special considerations for biologics?

$4 \mathrm{~d}$. What is your process for determining whether specific management tools will be required (e.g., step therapy provisions, prior authorization, copayment/ coinsurance tier)?

4e. What is the timing of the technology assessment/review process?

- Does this vary by product or indication and in what ways? How often is evidence/treatment updated?

- Does the organization track products that are in the pipeline and not yet available in the market? How and when are these products assessed?

- Do these assessments include single product assessments, class or disease assessments, or a mixture?

4f. At what point is a coverage policy written? Is the team that develops the coverage policy different than the health technology assessment team? How and in what ways do their roles differ?

4h(i). Does the results of a drug review influence the following? If so, in what way and during what stage of the drug review process?

- Tier assignment

- Need to negotiate discount or rebates

- Need to negotiate risk sharing agreements

- Need to negotiate other contractual agreements

- Disease management efforts

- Overall cost and volume considerations

- Decision to have ongoing assessment/monitoring of costs and outcomes associated with a newly-covered product

4h(ii). How does this vary by disease area (e.g., rare vs. common disease, most costly indication areas) and treatment type (examples)?

4i. Are there other factors in your organization that currently influence if and how a product is covered by your plan? For example, do you have special population(s) to consider? Company mission or vision? Can you name others?

$4 \mathrm{j}$. Which of the following external factors influence the technology assessment process? What level of influence do they have and under what circumstances are they influential?

\begin{tabular}{|l|c|c|c|c|c|}
\hline & \multicolumn{5}{|c|}{$\begin{array}{c}\text { Influence scale (1-5) } \\
\text { External factors }\end{array}$} \\
\hline Key opinion leaders & 1 & 2 & 3 & 4 & 5 \\
\hline Advocacy organizations & 1 & 2 & 3 & 4 & 5 \\
\hline Media & 1 & 2 & 3 & 4 & 5 \\
\hline Business trends & 1 & 2 & 3 & 4 & 5 \\
\hline Manufacturers or industry associations & 1 & 2 & 3 & 4 & 5 \\
\hline Quality measures & 1 & 2 & 3 & 4 & 5 \\
\hline Employers groups or unions & 1 & 2 & 3 & 4 & 5 \\
\hline Other (please describe) & 1 & 2 & 3 & 4 & 5 \\
\hline
\end{tabular}

\section{FUTURE CONSIDERATIONS AND WRAP-UP}

5a. How do you see your organization's existing technology assessment process changing in the future? For example, we seem to be moving towards personalized medicine, so how will your organization account for diagnostic tools and companion drugs in the future?

Are there other developments that may impact the way you do technology assessment?

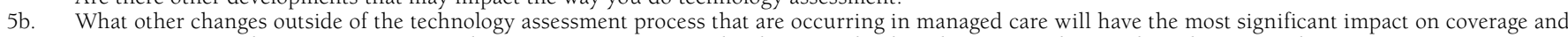
access? For example, some organizations have or are moving towards adopting value-based insurance designs, how do you see these insurance programs affecting the way technology assessment is conducted? 